\title{
Thai Traditional Medicine: Applying Local Wisdom Knowledge for Health Treatment of Cancer Patients in Aphinyana Arokhayasala Foundation
}

\author{
Sayan Promdee ${ }^{1}$, Anchalee Jantapo ${ }^{1} \&$ Wisanee Siltragool ${ }^{1}$ \\ ${ }^{1}$ Faculty of Cultural Science, Mahasarakham University, Muang District, Maha Sarakham 44000, Thailand \\ Correspondence: Sayan Promdee, Faculty of Cultural Science, Mahasarakham University, Muang District, Maha \\ Sarakham 44000, Thailand. E-mail: Promdee_s@outlook.co.th
}

Received: April 19, 2014 Accepted: May 23, 2014 Online Published: June 12, 2014

doi:10.5539/ach.v6n2p126

URL: http://dx.doi.org/10.5539/ach.v6n2p126

\begin{abstract}
Local wisdom knowledge concerning health care and treatment of cancer patientshas been handed down to Thai people who intent to study in this field. The Thai traditional practitioners working for Aphinyana Arokhayasala Foundation and using a Thai traditional medical examining and diagnosis to classify the patients into some kinds of cancer. They compound herbal medicine to treat their patients according to their symptoms and kinds of cancer. All patients staying in this Foundation are looked after by modern physicians, Thai traditional physicians, relatives, and service-minded volunteers and are treated with a combination of herbal medicine, exercise, and Buddhist meditation. This research will reflect all details of the application of indigenous knowledge for health treatment of cancer patients. Organizations concerned can use some ideas from the research results for treating their patients. Organizations concerned can use some ideas from the research results for treating their patients.
\end{abstract}

Keywords: Thai traditional medicine, wisdom knowledge, health treatment, cancer patients, Aphinyana Arokhayasala Foundation

\section{Introduction}

Local wisdom knowledge oncerning Thai traditional medicine is a body of knowledge compounded with accumulative experiences through the knowledge management process of learning, selecting, improving, developing, and perpetuating. This knowledge has been used a self-reliant system for solving sickness, preventing people from sickness, taking care of oneself and others, and adapting oneself to surroundings and the change of ages. It is a part of Thai Ways or a holistic approach to defeat cancer based on a Buddhist belief concerning the relation of body, mind, society, and surroundings. Thai Buddhists believe that if a person learns to balance his or her body with mind, society, and surroundings, he or she will be happy and not suffer from all difficulties so everyone should learn to conduct oneself appropriately in order to has good physical and mental health (Kanchanakun, 2004).

Thai traditional medicine based on folk medicine originated in Thai society around one thousand years ago. The identity of it is a particular diagnosis, the diagnosis made not only for finding the direct cause of illness but also finding the six of indirect cause of illness called Six Smutthana; namely, Dhatu Samutthana (a cause of illness resulted from the deviation of natural condition of the body), Ayu Samutthana (a cause of illness resulted from aging), Kala Samutthana (a cause of illness resulted from a change of time), Utu Samutthana (a cause of illness resulted from a physical inorganic change), and Padesa Samutthana (a cause of illness resulted from living in an unsuitable region). Thus, careless behavior of people leading to illness is an important cause apart from disease. Since human body composed of the four elements are the earth, the water, the air, and the fire so each patient should balance himself or herself carefully by conducting oneself in accordance with instructions of Thai traditional physician. The Thai physician compound herbal medicine according to a diagnosis of each patient and then the patient is treated with a combination of medication, exercise, and meditation. Self-treatment is a main concept of Thai traditional medicine, physicians, patients, family members, and community members participate in the process of treatment (Sapcharoen, 1997).

Cancer is not only a serious problem for Thai Public Health Organizations concerned but it is also for World Public Health Organizations concerned. Statistical figures have revealed that over six million people died from 
cancer all over the world or 13 percent of all deceased persons and about 9 million people are new cancer patients of every year. The World Health Organization anticipated that over 11 million people will be died by cancers in 2020. As for Thailand, the death rate resulted from non-contagious dying from cancers is the highest of all diseases or about $16.3 \%$ and most men died from liver cancer, while most women died from cervical cancer (Department of Planning and Statistics, National Cancer Institute. 2013: http://www.nmsurat.com /nmsurat joomla/2011-12-03-10-11-47.html).

Each of cancers strongly affects patients in terms of emotional condition, mental condition, family, social, and economic stability since it is a serious disease which needs a lot of money for medical treatment. As for a national level, cancer organizations concerned have to buy cancer-medicine, cancer-diagnostic instruments and others from countries mastering cancers with a large number budget so Aphinyana Arokhayasala Foundation was located at Wat Kham Pramong District, Sakon Nakhon Province in order to treat cancer patients with the integration of Thai traditional medicine, modern medicine, and alternative medicine. This foundation acts as a hospital for cancer patient treatment according to holistic treatment and Buddhist way.

\section{Purposes and Objectives}

The purposes of this research were as the following:

1. to investigate the background, situations, and difficulties of the application of Thai traditional medicine for cancer patient treatment.

2. to apply local wisdom knowledge on Thai traditional medicine for cancer patient treatment.

3. to investigate the application of local wisdom knowledge on Thai traditional medicine for cancer patient treatment of Aphinyana Arokhayasala Foundation

\section{Methodology}

A qualitative research method was used for finding out research results. Research data were collected by means of a documentary survey and a field study.

Aphinyana Arokhayasala Foundation located at Wat Kham Promong (Kham Pramong Temple), Sawang Subdistrict, Phanna Nikhom District, Sakon Nakhon Province was used as a research area.

Research population was the people living in Sakon Nakhon Province. A research sample of 84 people consisted of 6 key informants, 18 casual informants, and 60 general informants.

Research instruments used for collecting data were a survey an interview, an observation, and a focus group discussion.

A triangulation technique was used for examining data. The data were analyzed according to research purposes and research results were presented by means of a descriptive analysis.

The researchers conducted this research as follows:

1. a stage of collecting data, the researchers set the date of interview together with the director of Aphinyana Arokhayasala Foundation and then went there to interview 6 key informants, 18 causal informants, and 60 general informants. All of them consisted of directors, alternative medical doctor, Thai traditional doctors, medical doctors, alternative medical doctors, healers, pharmacists, voluntary nurses, cancer patients, relatives of cancer patients, and other people concerned. These data were the primary data.

2. a stage of rechecking the data, the research set the date of holding a focus group discussion and workshop together with the director of this foundation and then went there to hold the focus group discussion and workshop in order to recheck the primary data and to complete them. All of data were collected for answering all research purposes.

3. a stage of classifying, analyzing and synthesizing the data, the researchers classified the data into their groups, each group of the data was analyzed for supporting the answer of each research purpose. The analyzed data were synthesized and rewritten as the whole of research results.

4. a stage of presenting the results, the researchers presented the results according to research purposes through multimedia systems, a research report, and other materials at a research forum of the university.

During collecting-data duration, the researchers often observed and recorded the process of cancer-patient treatment operated by all staff of Aphinyana Foundation. An observation, an interview, a focus group discussion, and a workshop were main instruments of this research. 


\section{Results and Discussion}

1. The background, situations, and difficulties of the application of Thai traditional medicine for cancer patient treatment. This result has revealed the following:

Most practitioners of Thai traditional medicine inherited this indigenous knowledge from their fathers, palm-leaf scriptures, and a pharmacopoeia of Wat Pho. The practitioners passing the medical professional test received licenses to practice medicine in Thai traditional medicine and acted as the experts transmitting this knowledge to medical students. They were given the right to treat patients according to the law.

Normally the practitioner of Thai medicine makes a diagnosis for a cancer patient by touching, questioning the patient about symptoms, and date of birth in order to know the identity of elements of the patient and the cause of cancer according to an astrological calculation. Afterwards, the patient conducts himself or herself in accordance with the practitioner's instructions; for example, drinking herbal solution, doing exercise, eating fruit and vegetables, eating easy digestive food, doing meditation, Chanting Buddhist chants, offering food to monks, singing, and making useful things. The cancer patients staying in Aphinyana Arokhayasala Foundation are looked after by Thai traditional physicians, relatives, and service-minded volunteers. This is consistent with research result of Saowapha Phornsiriphong and others (1996), it has revealed that each of Thai traditional physicians tends to make a diagnosis according to an astrological calculation, the result from the calculation can indicate that what cause made the patient ill such as dyspepsia, a change of weather, air pollution, contraindicated food, a seasonal change, and evil power. Kritsada Sithamma and others (2008) also support that the practitioners of traditional Thai medicine living in northeastern Thailand integrate physical and mental treatment together, physical illness of patients is relieved by treating them with herbal medicine compounded of herbs, some parts of animal's body, and local minerals, including Thai traditional massage, as for mental illness of patients is relieved by holding a ritual for invoking the spirits for blessings and encouragement for the patients.

The difficulties of cancer patient treatment are lack of herbs, herbal medicine is difficult for cancer patients to take, the patients do not strictly conduct themselves in accordance with practitioners of Thai traditional medicine, service-minded volunteers, and officers, lack of the experts in the field of cancer patient treatment, and a majority of patients are too weak because they lose their appetite. This is consistent with research result of Saowapha Phornsiriphong and others (1996), it has revealed that a stomach is vital organ supporting all kinds of food which people ate so some potent medicine or contraindicated food may make people feel ill.

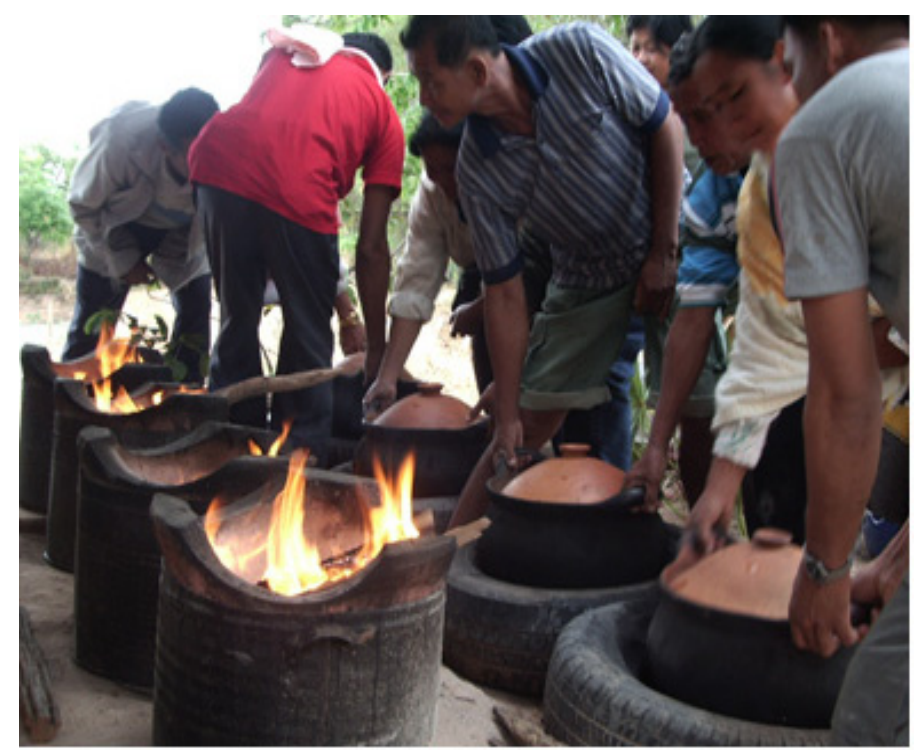

Figure 1. Patients and their relatives participle in a ritual of herbal boiling 


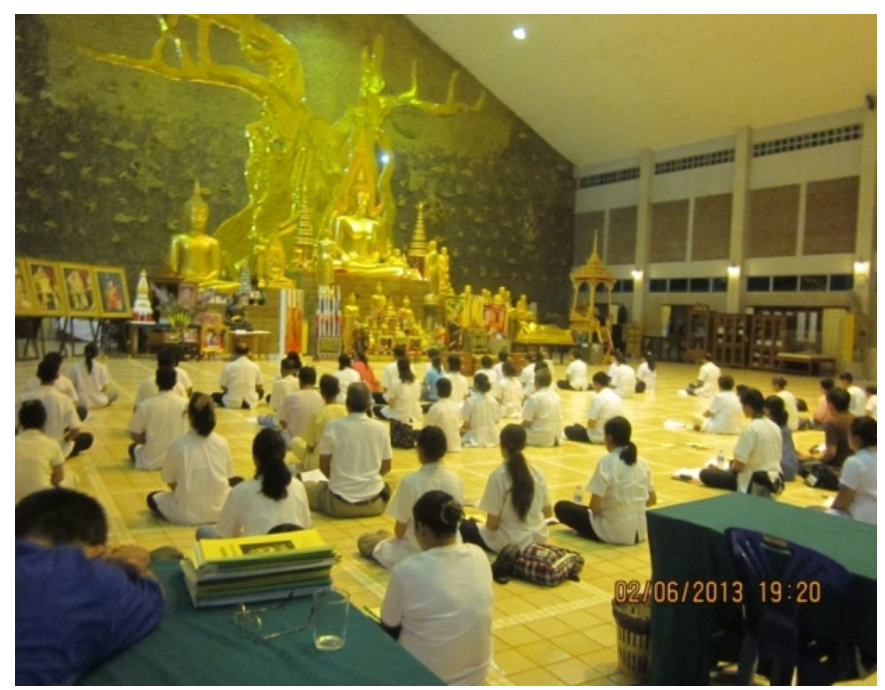

Figure 2. Voluntary staff participate in meditation theraphy together with cancer-patients

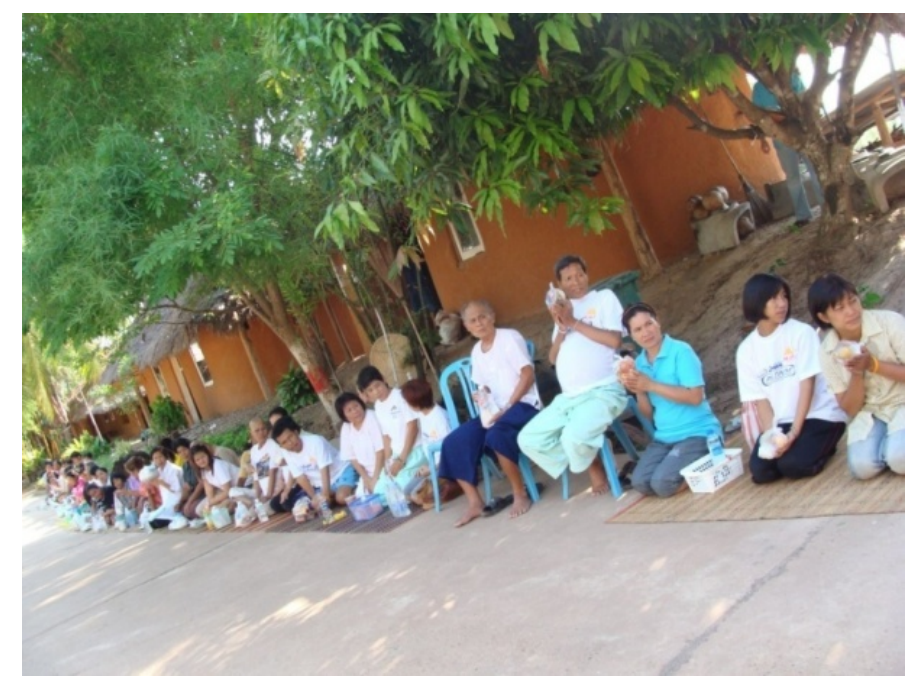

Figure 3. Cancer-patientsandtheir relatives are waiting for offering food for the founder-monk

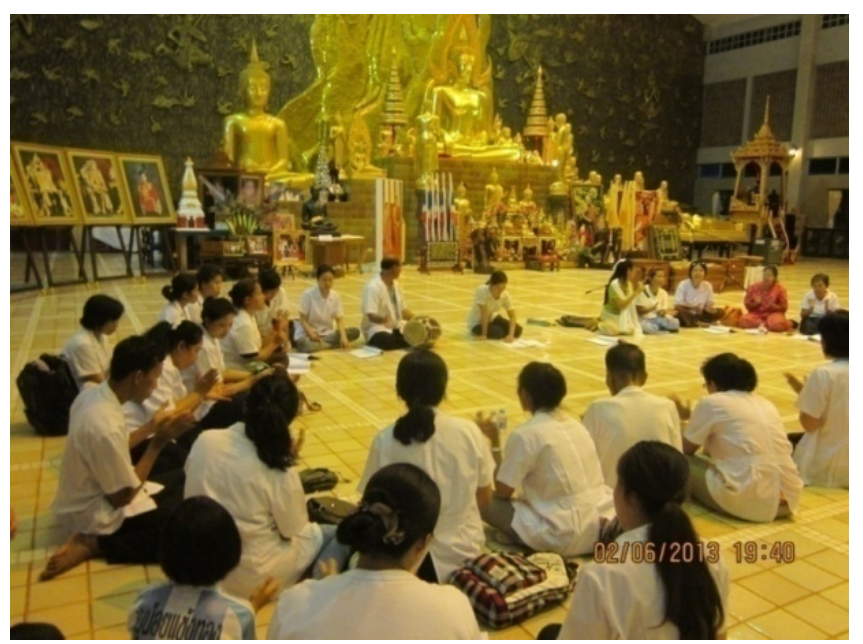

Figure 4. Caner-patients and voluntary staff are singing together 
2. The application of local wisdom knowledge on Thai traditional medicine for cancer patient treatment. This result has revealed the following:

Aphinyana Arokhayasala Foundation looks after cancer patients by integrating traditional Thai medicine, modern medicine, and alternative medicine in order to revive balance of elements (earth, water, air, and fire) of the patients. Some names of herbal medicine for reviving balance of four elements of the patients are Ya Benchakun Pataravej Siam, Ya Tri Phala Pataravej Siam, Ya Tri Ka Tok Pataravej Siam, Ya Tri San Pataravej Siam and Ya Ha Rak Pataravej Siam. In case of the patients have complications such as a cough, a contusion, a swell, a sprain, a diarrhea, flatulence, and colic, herbal medicine such as Phaya Yor, Khamin Chan, Fa Thalai Chon, or Pru Kao will be selected for treating each patient according to his or her symptom. Each patient must eat food according to the identity of elements of his or hers, vegetables, fruits, and fruit juices are served for reviving the patient's balance of elements. Stretching exercise called Ruesi Datton is usually used for reviving balance of four elements of all patients together with making meditation, chanting Buddhist chants, and singing. Pressure-checking instruments, pulse-checking instruments and other modern medical instruments are used for checking the patients' health. This is consistent with research result of Pha Khru Inthasan Wichak Intha Saro Kitrai (2008), it has revealed that diseases in terms of Buddhism have 2 kinds: 1) physical disease, and 2) mental disease, thus 5 kinds of herbal medicine are used for treating sick people for physical disease but Buddhist Dharma medicine is used for treating sick people for mental disease. The Buddhist Dharma medicine consists of Bojihanga (the seven enlightenment factors) and Sanna (the ten perceptions as objects of meditation), including Sappaya (the seven advantageous conditions) which are suitable abode, suitable resort, suitable speech, suitable person, suitable food, suitable climate, and suitable posture.

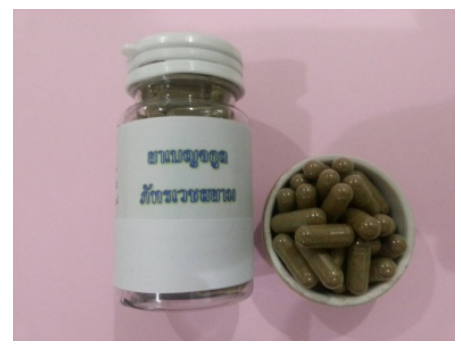

Ya Benjakun Pataravej Siam

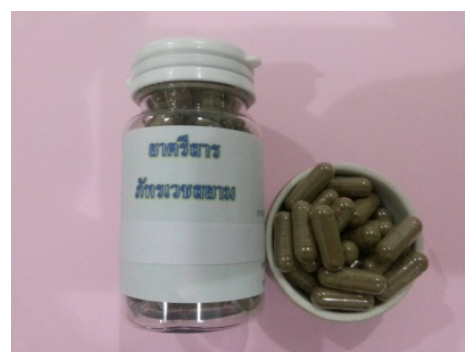

Ya Tri San Pataravej Siam

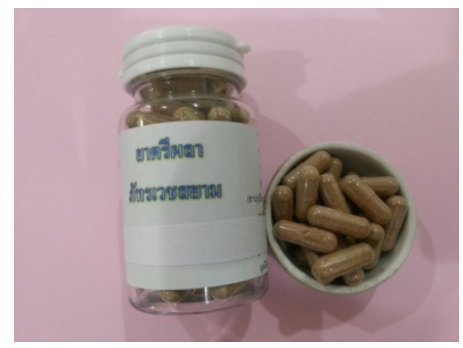

Ya Tri Phala Pataravej Siam

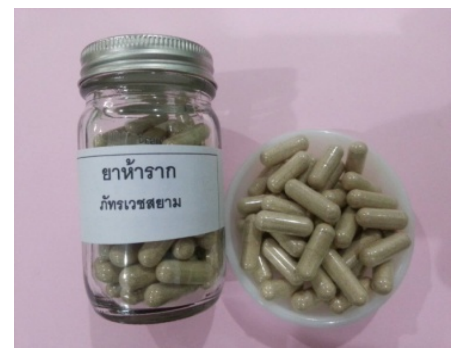

Ya Ha Rak Pataravej Siam

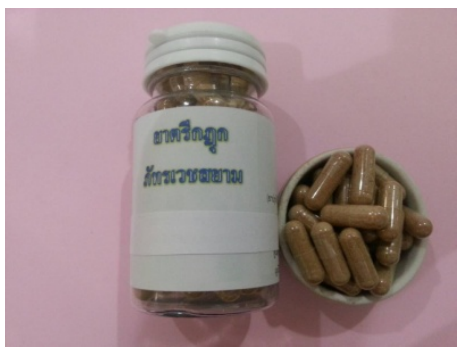

Ya Tri Ka Tok Pataravej Siam

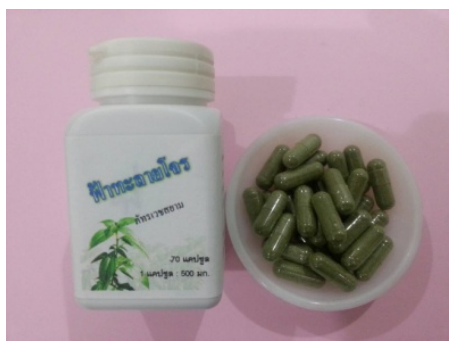

Fa Thalai Chon

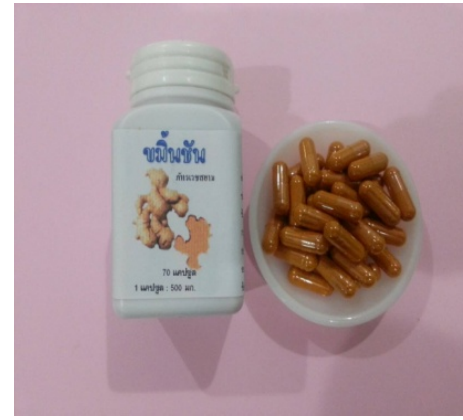

Khamin Chan

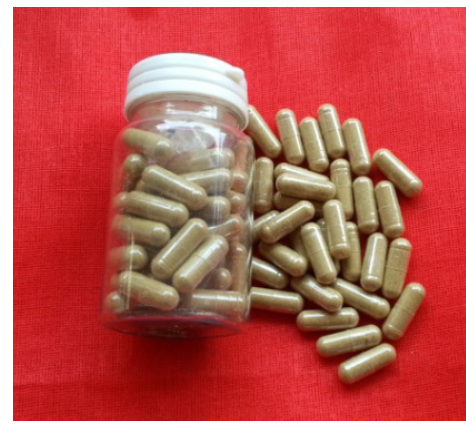

Pru Kao

Figure 5. Some samples of herbal medicines of Aphinyana Arokhayasala 
3. The application of local wisdom knowledge on Thai traditional medicine for cancer patient treatment of Aphinyana Arokhayasala Foundation. This result has revealed the following:

Aphinyana Arokhayasala Foundation focuses on the integration of Thai traditional medicine, alternative medicine, and modern medicine for cancer patient treatment in order to encourage balance of elements of the patients and this method of treatment will benefit each patient in terms of maintaining physical and mental health Thus, cancer patients can lead their long lives or in case of a cancer patient of the end stage, he or she will pass away serenely. The application of local wisdom knowledge on Thai traditional medicine for cancer patient treatment of Aphinyana Arokhayasala Foundation shown through the Figure 6.

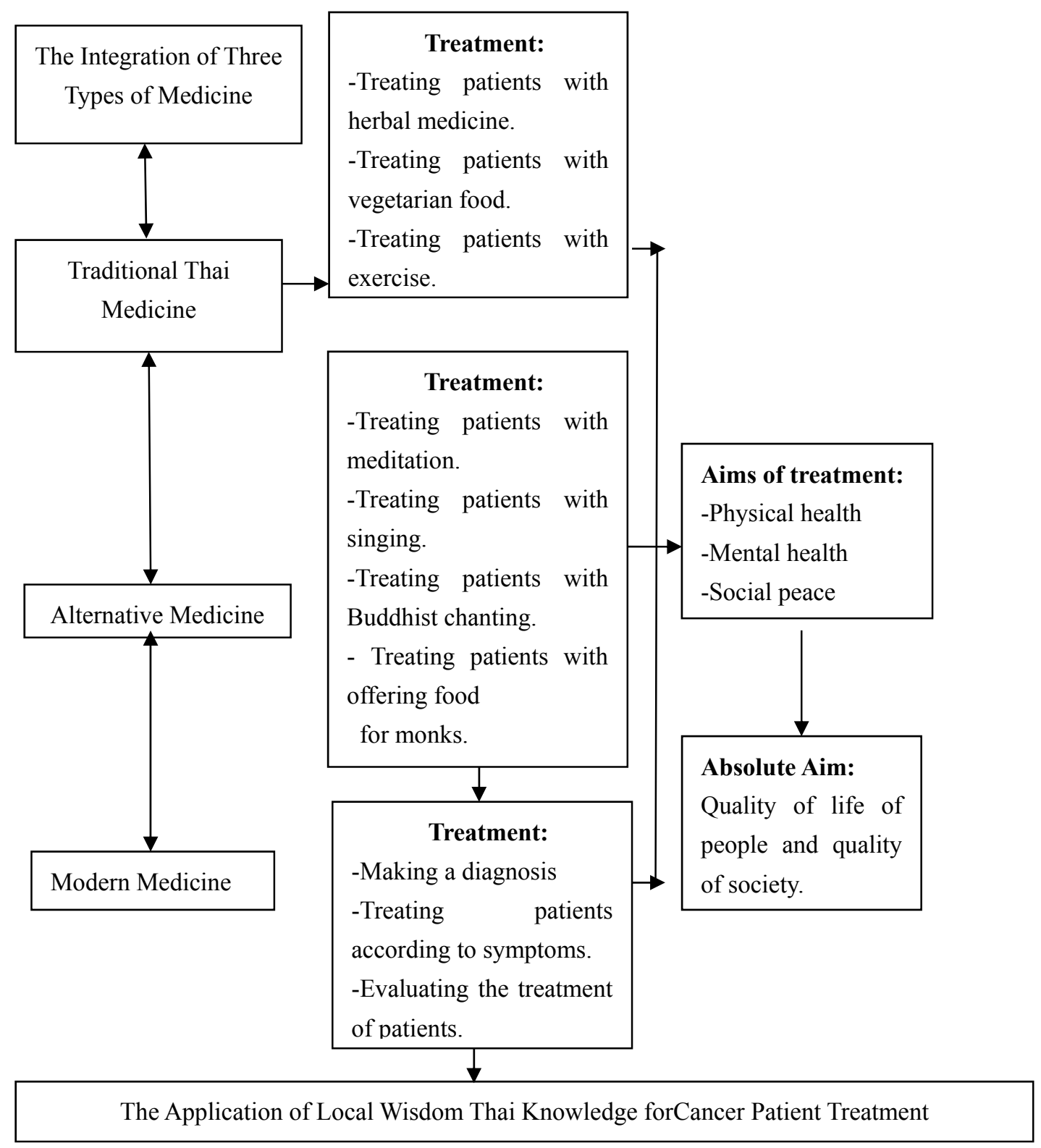

Figure 6. The application of local wisdom knowledge on Thai traditional medicine for cancer patient treatment of Aphinyana Arokhayasala Foundation

As for the results of the application of local wisdom knowledge for cancer patient treatment, it has revealed that all persons who work for the foundation cooperate in looking after patients' health in many ways. Traditional Thai medicine, modern medicine, and alternative medicine are integrated for the best treatment. Thus, positive results from cancer patient treatment of the foundation are the patients feel secure staying there, the patients' relatives feel trust in the treatment of the foundation, the medical practitioners, officers, and service-minded 
volunteers feel pleased with working for cancer patients, including the foundation plays a role of a social welfare organization. The useful things are shown through the Figure 7.

\section{The Results of The Application of local wisdom Knowledge for Cancer Patient}

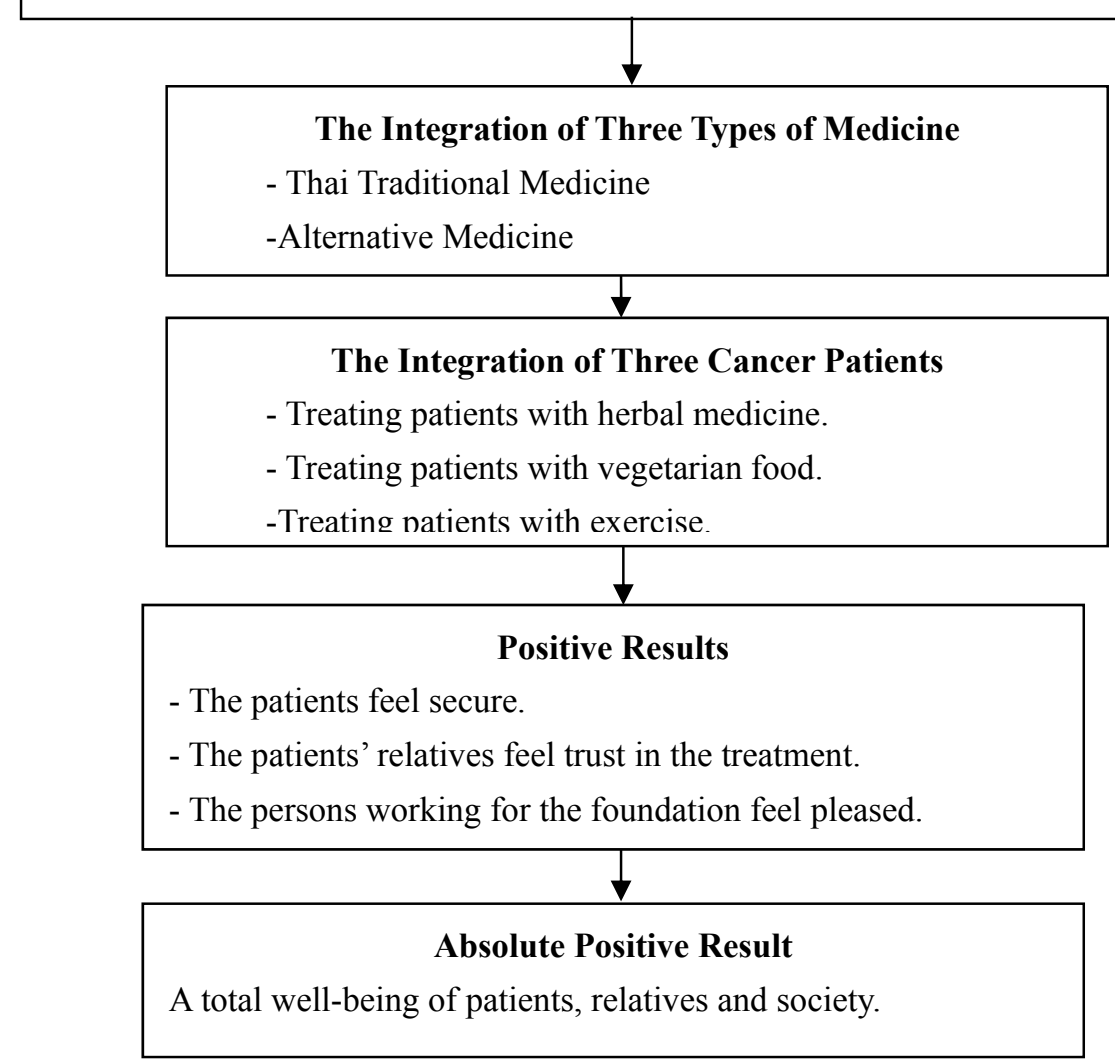

Figure 7. The results of the application of local wisdom knowledge for cancer patient treatment of Aphinyana Arokhayasala Foundation

\section{Conclusion}

Applying local wisdom knowledge for health treatment of cancer patients of Aphinyana Arokhayasala Foundation is a good sample of all organizations that play a role as the social welfare foundations. The organizations concerned can adapt these research findings to their medical treatment for cancer patients or others. This is a good way for encouraging a total well-being of society.

\section{Acknowledgements}

This research was supported by Faculty of Cultural Science, Mahasarakham University. Authors are thankful to people for data, the sample living in Sakon Nakhon Province and all of the support provided.

\section{References}

Department of Planning and Statistics, National Cancer Institute. (2013). The Statistics of Cancers of Thailand. Retrieved from http://www.nmsurat.com/nmsurat joomla/2011-12-03-10-11-47.html

Inthasaro, P. I. (2008). A Study of Herbal Medicines and Dharma Treatment Found in Buddhist Cannon. Master Degree's Thesis. Bangkok: Mahachulalongkornrajavidyalaya University.

Kanchanakun, K. (2004). Dhammanamai Thai Way of Life and Indigenous Thai Knowledge on Thai Traditional Medicine. Nonthaburi: Sukhothai Thammathirat Open University Press.

Pornsiripong, S., et al. (1996). Indiginous Knowledge on Massage: A Case Study of Phoyaichan Ken Lawong. Journal of Language and Culture, 5(2), 42-46.

Sapcharoen, P. (1997). Thai Traditional Medicine the Holistic Medicine. Nonthaburi: Institute of Thai Traditional Medicine, Department of Medical Services, Ministry of Public Healt. 


\section{Copyrights}

Copyright for this article is retained by the author(s), with first publication rights granted to the journal.

This is an open-access article distributed under the terms and conditions of the Creative Commons Attribution license (http://creativecommons.org/licenses/by/3.0/). 